\title{
Perceptions in English For Academic and Professional Purposes Competencies: An Analysis of TVL Class
}

\author{
Irene Claire P. Herida \\ Abra State Institute of Sciences and Technology, Philippine \\ e-mail: ireneclaireherida@gmail.com \\ Alexis Arizabal- Enriquez \\ Abra State Institute of Sciences and Technology, Philippine \\ e-mail: enriquezasist@edu.ph \\ Article History: Received on 15 February 2021, Revised on 19 February 2021, \\ Published on 21 February 2021
}

\begin{abstract}
This study identified the students' perceptions in English for Academic and Professional Purposes. This study employed the descriptive research design to describe the perceptions of the respondents in the different competencies of the course on English for Academic and Professional Purposes. The researcher-made statements comprised a 5point -scale that range from always to never in identifying the perceptions. There were 15 students who participated and validated such examples were gained or not at all taught by their respective teacher. Results of the study say that, "I was taught of the language used specifically formal language in academic texts from various disciplines" has the highest $\overline{\mathbf{x}}$ (4.6) followed by the statement, "I learned to form opinions based on facts", $(\overline{\mathbf{x}}=4.47)$, "I learned how to summarize the content of an academic text", "I was taught to cite specific sources to support claims and I learned to present ideas convincingly" $(\overline{\mathbf{x}}=4.4)$. Consequently, the statement, "Using the appropriate language for a specific discipline was taught to me" $(\overline{\mathbf{x}}=4.3)$, "My teacher explained how to make research topics" ( $\overline{\mathbf{x}}=4.27)$, thus, the respondents positively perceived English for Academic and Professional Purposes.
\end{abstract}

Keywords: English for Academic and Professional Purposes, K12 Curriculum, Academic Writing

\section{A. Introduction}

One of the subjects from the K12 Curriculum is English for Academic and Professional Purposes served to the Senior High School students. Gillet (ND) discloses that this course refers to the language and associated practices that people need in order to undertake study or work in English medium. It helps these people learn some of the linguistic and cultural - mainly institutional and disciplinary - practices involved in studying or working through the medium of English. The teaching content is explicitly matched to the language, practices and study needs of the learners. It is goal directed - the learners are not learning the English language for the sake of it, but because they need, or will need, to use English in their professional or academic lives. They are usually current higher education students or members of staff or they are hoping to go on to higher education. They need to learn English in order to succeed in their academic careers. It must be based on an analysis of needs, which aims to specify as closely as possible exactly what it is that the learners have to do through the medium of English. This means taking into account of the opinions of all the various stakeholders. For an undergraduate 
student, this could mean the learner, his or her parents, and sponsors, present and future lecturers, examiners, administrators, materials writers etc.

This involves an attitude to learning and teaching that believes that it is possible and useful to specify what language and linguistic practices are required in a particular academic context and that it is worthwhile to focus teaching on this. One important feature of such course is the close attention that is paid to the learners' aims and what they are working on, studying or planning to study. It is also important to take into account the learning or study needs of the students, what they need to do in order to learn the language. Teachers find out exactly why the learners are learning English and what language and practices they will need to pay attention to.

The Abra State Institute of Sciences and Technology in the Bangued Campus embraced the challenges posited by the K12 Curriculum. It offers STEM, HUMSS, TVL with various strands. The scarcity of materials had been a perennial problem on the advent of the implementation of the Curriculum. There had been a lot of seminars and forums conducted as to the development of instructional materials just to help the faculty of the College in their teaching. It is then the parameter of this study to look into the perceptions of the TVL class as their learning of the subject, English for Academic and Professional Purposes in such a way to encourage the researchers on developing an instructional material suitable for them aligned with the competencies and their own needs.

Writing in the Disciplines is often referred to as English for Academic Purposes (EAP) in the UK and Canada. Jordan (2002) and Afful (2007) states that EAP in the UK arose in response to the increasing internationalization of tertiary education , while Bazerman \& Russell,(1994) are of the view that Freshman's Composition and other allied programs in the USA arose as a response to the obvious decline in the quality of writing of students.

Today, EAP is spreading fast as the result the demand for English in the world, especially in the academia. According to Diane (2009), EAP is one of the types of ESP, tailored to the needs of the learners at various levels. Afful (2007) is of the view that a key course that is taught in many English-medium universities to facilitate the acquisition of academic literacy skills is English for Academic Purposes (EAP). This is because EAP is taught based on the needs or reasons for learning English. The teaching of EAP begins with the analysis of the students' linguistic background, what they have known and what they need to know. Diane (2009) citing Dudley-Evans \& St. John, 1998; Robinson, 1991, opines that this commitment to the purposes of the learners themselves is, to reiterate, what unites all the various branches of ESP. What the commitment entails is (1) first and foremost (before, during, and even after instruction), finding out what learners' needs are, then (2) developing or adapting materials and methods to enable needs-responsive instruction while concurrently (3) acquiring the expertise to function as needs-knowledgeable instructors. The study was based on the theory and practice of English for Specific Purposes (ESP).The concept of ESP has various definitions. According to Hutchinson and Waters (1987), ESP is an approach to Language Teaching in which all decisions as to the content and method are based on the learners' reason for learning. This means that it is a learner-centered approach to the teaching of English Language. The term ESP stands for English for Specific Purposes. It is a linguistic field of study that addresses the immediate and very specific needs of learners for a target language which is required for academic or professional purposes (Hossain 2013). Similarly, Richards and Schmidt (2010) in Mohammadi \& Mousavi (2013) describe English for Specific Purposes (ESP) as "a language 
course or program of instruction in which the content and aims of the course are fixed by the specific needs of a particular group of learners".

Practically, speaking, ESP deals with preparing the Learners' to be able to use English in academic (students of different fields), professional (people of different professions such as doctors, engineers, and nurses), or workplace (technicians for example) settings. As it is about specific students, therefore, it must be tailored to the needs of these students. ESP is also often defined in terms of communicative competence. McArthur (1996) for instance, describes ESP as a communicative based approach to the designing and teaching of English as against the traditional teaching of it as a second or foreign language. It is the English Language Teaching programme designed to meet the learners' needs in specific professional contexts. ESP is the English Language taught for professional, vocational and other specific purposes that originated in course of business English for foreign learners. It was developed in the 1960s in response to the demand for courses geared towards practical and functional rather than educational and cultural end. Planning ESP courses starts with needs analysis to establish the limits of the language that the learners need. According to Salto Youth, a needs analysis attempts to collect as much information as possible in order to build a comprehensive understanding of the needs and issues facing your NA. Once those needs are understood, it is a lot easier to identify potential solutions. Focus on the learners' needs became as important as the method of teaching employed. These factors gave birth to the need for special language and method of teaching.

Today the need for English at the local, national and international arenas cannot be over emphasized. The computer and the internet technologies have shrunken the world making it a global village. In academia, the demands for English seem to be more than other linguistic domain. English serves as medium of instruction in many institutions of learning in the world. EAP is a branch of EOP which is a branch of ESP associated professions. This branch of ESP is constantly expanding and generating off shoots such as English for Business Purposes (EBP), English for Legal Purposes, (ELP), English for Medical Purposes among others. EAP is taught in education domain to enable the students pursue their course studies effectively and efficiently. Like ESP itself, it is taught based on the needs of the learners or their reasons for learning English. The demand for English in academic and occupational settings led to the quest for better and appropriate methods of teaching. EAP rather than General English in institutions of learning today has revolutionized the way English is taught. EAP programs in most of the developed countries today are designed based on the needs of the students of particular disciplines. Hutchinson and Waters (1987) popular slogan 'tell me why you need English and I tell you the English you need' remains the guiding principles of designing and teaching EAP programs in academic settings. It is against the above background that this paper examines how EAP approach enhances the students' proficiency in English better than other approaches. EAP as a branch of ESP is taught in higher institutions to improve the learners' proficiency in English Language and to help them to overcome some of their difficulties in English as a medium of instruction and communication. The first stage in the teaching of EAP is to assess why the students are learning English and the skills they need. This is what is called in the study of ESP needs analysis.

Jarvis (2001) points out that in British Universities, English for academic purposes courses form an important language provision for non-native speakers (NNS). Jarvis ( 2001) also points out that EAP courses can be either pre -sectional, where students take the course before they go into further academic study or in-sessional, where students study while already on academic 
Volume 1 (3) 2020

E-ISSN: 2723-6919 P-ISSN:2746-0827

course. The pre-sessional EAP program is designed to provide the learners of English as a foreign language with Basic English Language Skills that will enable them to pursue their academic course of study in English. The in-sectional on the other hand is taught to the learners of English as a second language to improve their proficiency in English. The common core EAP focuses on general academic language skills, while the subject specific EAP looks at the language features of particular discipline. In common core EAP, students of different course backgrounds are taught the same language skills which may not have direct bearings on the students' academic course of study. The aims of teaching the two however is to equip the students with the language skills that will enable them follow their academic fields of study. Focus is made on the need to raise the students' English to enter higher institutions or study successfully.

This study identified the students' perceptions along the following competencies in their subject, English for Academic and Professional Purposes: structure of a specific academic text, language used in academic texts from various disciplines, specific ideas contained in various academic texts, text structure to glean the information he/she needs, techniques in summarizing a variety of academic texts, thesis statement of an academic text, paraphrase/ explain a text using one's own words, outline reading texts in various disciplines, summarize the content of an academic text, write a précis/abstract/summary of texts in the various disciplines, form opinions based on facts, cite specific sources to support claims, present ideas convincingly, use the appropriate language for a specific discipline, raise legitimate, contrary views in an appropriate manner, use appropriate critical approaches in writing a critique such as formalism, feminism, etc., apply the principles of writing effective reviews and critiques, and write an objective/balanced review or critique of a work of art, an event or a program.

\section{B. Methods}

This study employed the descriptive research design to describe the perceptions of the respondents in the different competencies of the course on English for Academic and Professional Purposes. The researchers cited specific statements for each competency for the respondents to validate, from always to never, if such examples were gained or not at all taught by their respective teacher. The researcher-made statements comprised their perceptions of the purposively 15 selected TVL students in English for Academic and Professional Purposes. The teacher-made questionnaire was given to the students through google forms.

\section{Results and Discussion}

Focusing on the objective of this study, the researchers found that the respondents have various perceptions towards English for Academic and Professional purposes. The table below shows the perceptions of the students in the different areas.

Table 1: Perceptions of the TVL Students in the Different Areas

\begin{tabular}{clc}
\hline No. & \multicolumn{1}{c}{ Statements } & Mean \\
\hline 1 & $\begin{array}{l}\text { I learned the structure-introduction, body and conclusion of a specific } \\
\text { academic text. }\end{array}$ & 4.13 \\
2 & $\begin{array}{l}\text { I was taught of the language used specifically formal language in } \\
\text { academic texts from various disciplines. }\end{array}$ & 4.6 \\
3 & I learned the specific ideas contained in various academic texts. & 3.93 \\
&
\end{tabular}


4 My teacher taught me to glean the information I need in the text structure.

5 I was taught how to summarize various articles

6 My teacher explained how to make research topics

7 Paraphrasing or rewording various statements was taught to us

8 I learned how to outline articles and other texts in different ways

9 I learned how to summarize the content of an academic text.

My teacher taught me to write a précis/abstract/summary of texts in the various disciplines.

11 I learned to form opinions based on facts.

12 I was taught to cite specific sources to support claims.

13 I learned to present ideas convincingly.

Using the appropriate language for a specific discipline was taught to me.

My teacher taught me to raise legitimate, contrary views in an appropriate manner.

I learned to use appropriate critical approaches in writing a critique such as formalism, feminism, etc.

Apply the principles of writing effective reviews and critiques was taught to me. art, an event or a program.

As gleaned from the table above, the statement, "I was taught of the language used specifically formal language in academic texts from various disciplines " $(\overline{\mathbf{x}}=4.6)$, "I learned to form opinions based on facts", ( $\overline{\mathbf{x}}=4.47)$, "I learned how to summarize the content of an academic text, I was taught to cite specific sources to support claims and I learned to present ideas convincingly" ( $\overline{\mathbf{x}}=4.4)$, "Using the appropriate language for a specific discipline was taught to me" ( $\overline{\mathbf{x}}=4.3)$, My teacher explained how to make research topics" $(\overline{\mathbf{x}}=4.27)$.

From the statement, I was taught of the language used specifically formal language in academic texts from various disciplines, it means that the formal language or using the formal language in writing academic texts was commonly used by the respondents. This can be supported by the respondent's answer in a semi structured interview when asked about the topic that liked the most, "The topic about formal and informal languages, because in this topic I learned where to use words properly". It was inculcated in their minds that the formal language is used for academic texts. It can be deduced also that the respondents were familiar with formal language 
already. The result of the study affirms with Gillett (1996) that academic writing prepares students for academic writing tasks. These tasks vary very much from writing short answers in exams to writing dissertations and theses. Of course, accurate grammar, punctuation and language use forms an important component of an EAP writing class, along with specific teaching of the formal language required. This will involve the teaching of the different text types, linking words, signposting expressions, introductions and conclusions. The respondents learned to form opinions based on facts and thus this has become the topic that one of the respondents liked the most. They can distinguish a fact from an opinion and thus it helped them to do right in the writing of the academic papers. Since these statements, I learned how to summarize the content of an academic text, I was taught to cite specific sources to support claims and I learned to present ideas convincingly were considered to have a high mean, the respondents perceived those as always, a part of their writing tasks specifically with academic papers. One of the respondents stated, "The importance of citations is the topic that I have liked a lot because this topic gives me knowledge on how to properly give certainty to the reader that the material, they are writing is proved previously." It means that the respondent was aware of the function of citations especially when it deals with writing. It has come to know that it is very important to acknowledge the work of other people that one has used in his or her writing. Further, from this, one of the respondents considered this as the most enjoyable activity by stating, "The activity in citations is the most enjoyable because we have gained knowledge on how to give assurance to a reader for the material that we are writing." Thus, the respondents can cite the sources to prove his or her claim; then summarize it for him or her to present his or her ideas convincingly.

Academic writing requires critical skills, such as the selection of topics, organization of ideas in clauses, paragraphs and the global text. With the statement, Using the appropriate language for a specific discipline was taught to me, the respondents were able to use the appropriate language in each of the academic papers. They were apprehensive on how to use the formal language in writing academic papers such as concept, position and reaction papers. In this way, one of the respondents positively stated that, "Yes of course, it really widens our understanding in making formal language that we can use in our everyday living", when asked about the benefit of taking this subject". This leads to saying, "They need to appreciate the role of language in communication and also know the meaning of words used in context, as well as the central ideas contained in each of the selection", by one of the respondents as his or her recommendation to his or her fellow students.

In understanding the subject, the teacher factor is very important. Most of the respondents know the role of teachers in teaching a subject. Likewise, with the statement, My teacher explained how to make research topics, the teacher has a great impact in teaching the subject. The following are the respondents' answers when they were asked about how they were motivated by their teacher in the conduct of their class:

S1: "Giving us a sense of ownership that allows us to feel accomplished and encourage us become active in class."

S2: "She explains everything for us to easily understand."

S4: "I was motivated by our teacher's quotation that says, "English is just a language and not a measurement of intelligence".

S6: "Ensure the classroom rules are detailed so student feel safe to participate and share their opinion and comment without ridicule".

S12: "I was motivated to write more about my opinion for others to read". 
Dudley-Evans (1980) believe that the language teacher needs to be able to grasp the conceptual structure of the subject his students are studying if he is to understand fully how language is used to represent that structure; to know how the range of different subjects are taught during the course; and to observe where and how difficulties arise in order that he can attempt to help both student and subject teacher to overcome them.

It is true then that teachers find out exactly why the learners are learning English and what language and practices they will need to pay attention to, according to Gillet (ND). As a whole, the respondents gave a positive perception in learning Academic and Professional Purposes ( $\overline{\mathbf{x}}=4.19$ ). The respondents learned vastly from this subject that dominates with their responses as to the benefits of learning the subject as TVL students. The following are their responses:

S1: "Yes, it helps us to improve our skills and to know how to write a text and know the importance of it."

S2: $\quad$ "Yes because more topics, more knowledge. This is my job as a student to maintain all facts and necessary values."

S5: "Yes, for it benefits me perfectly because it can help us on our next journey-college."

S7: "Yes. it helps my communication skills a lot and about writing an article; I made statements/phrases/contents more understandable in a way that can be easily understood in reading it for once."

S12: "Yes, because it taught us the proper ways and structures of essays or academic writings."

S13: "This helps us in our school interviews, in our research paper, business proposal and other formal letters, and other subjects like political science."

With this perspective, it can be supported by Gillet (ND) discloses that this course refers to the language and associated practices that people need in order to undertake study or work in English medium. Moreover, they need to learn English in order to succeed in their academic careers.

McArthur (1996) for instance, describes ESP as a communicative based approach to the designing and teaching of English as against the traditional teaching of it as a second or foreign language. It is the English Language Teaching program designed to meet the learners' needs in specific professional contexts. English for Academic and Professional Purposes serves as a means of improving and developing the necessary skills for the respondents to be engaged in the real world of learning. Thus, this benefits the respondents to be prepared for their journey to move one step up in the ladder of education.

\section{Conclusion}

In the realization of the objective of this study, English for Academic and Professional Purposes is perceived positively by the respondent, making it a tool for the improvement and development of their skills. Nevertheless, it is the subject that can be understood easily with the supervision of teachers that has his or her own unique way of motivating them. The students may continue and apply what they learned from the subject in their everyday life. Moreover, the teachers may continuously motivate the students and may find other strategies to teach the subject in the simplest and easiest way to understand it. 
Volume 1 (3) 2020

E-ISSN: 2723-6919 P-ISSN:2746-0827

E. Acknowledgement

We thank to the Rector Abra State Institute of Sciences and Technology and friends who have supported us to do this project. We would also like to thank our friends in who helped us a lot in completing this project.

\section{References}

Diane, B. (2009). English for Specific Purposes in Theory and Practice: What ESP Is and Can Be: An Introduction. from http://www.press.umich.edu/titleDetailDesc.do?id=770237 Michigan ELT, 2009.

Llego, Mark Anthony. (ND). English for Academic and Professional Purposes: Teacher's Guide. Retrieved from https://www.teacherph.com/english-for-academic-andprofessional-purposes-teachers-guide/.

M.F. Ruiz-Garrido, J.C. Palmer-Silveira, I. Fortanet-Gomez. Amsterdam: Rodopi, English for Professional and Academic Purposes. 2010. 237 pages, ISBN: 978-90-420-2955-2

Gillett, A. J. (1996). What is EAP? - Using English for Academic. Retrieved from http://www.uefap.com/articles/eap.htm

Hossain, Md. J. (2013). ESP Needs Analysis for Engineering Students: A Learner Centered Approach. Journal of PU, Part: B Vol.2, No.2, Presidency University.

Hutchinson T., \& Waters A. (1987). English for Specific Purposes. Cambridge, Cambridge University Press.

Jarvis, H. (2001). Internet usage of English for Academic Purposes courses. Cambridge, Cambridge, University Press. 